\title{
Commentary
}

\section{Tackling the social and structural drivers of HIV in Canada}

\author{
Rourke $\mathrm{SB}^{1,2,3^{*}}$, Bacon $\mathrm{J}^{1}$, McGee $\mathrm{F}^{4}$, Gilbert $\mathrm{M}^{1,5}$ \\ ${ }^{1}$ Ontario HIV Treatment Network, University of Toronto, Toronto, ON \\ ${ }^{2}$ Department of Psychiatry, University of Toronto, Toronto, ON \\ ${ }^{3}$ Centre for Research on Inner City Health, Li Ka Shing Knowledge Institute of St. Michael's Hospital, Toronto, ON \\ ${ }^{4}$ AIDS Bureau, Ontario Ministry of Health and Long-Term Care, Toronto, ON \\ ${ }^{5}$ Dalla Lana School of Public Health, University of Toronto, Toronto, ON \\ *Correspondence: sean.rourke@utoronto.ca
}

\begin{abstract}
There is new hope that we can significantly reduce HIV rates. The United Nations AIDS organization, UNAIDS, has challenged all countries to strive for aggressive targets that could significantly bend the curve on HIV infections and deaths: $90 \%$ of people living with HIV diagnosed; $90 \%$ of people diagnosed on treatment; and $90 \%$ of people on treatment virally suppressed. This new optimism is largely driven by strong research findings that early and ongoing HIV treatment improves individual health outcomes and reduces people's viral load, making them less infectious. However, the risk of HIV infection is far from evenly distributed among populations most at risk. Those most at risk will find it hardest to reach these targets as they are caught in a syndemic (synergistic epidemic) of intertwining health and social issues. Our research, and that of others, shows that those who are in a syndemic of co-occurring mental health, addiction and social issues (e.g. homelessness, food insecurity) are significantly more likely to fall out of care, less likely to adhere to treatment and less likely to achieve/maintain an undetectable viral load. Intervention studies have found that a combination approach to HIV prevention and treatment that goes beyond primary care and mental health tools to include social and structural interventions has a protective effect, and can reduce risk and improve adherence. People living with and at risk of HIV need better access to social and mental health services as well as clinical treatment services that will help them achieve and maintain optimal health and well-being. We strongly encourage those in the HIV sector across the country to identify a common vision, with clear goals and targets. With concerted and targeted efforts, a focus on program and implementation science, and a willingness to see and treat HIV as a social as well as a biomedical problem - the fourth decade of HIV in Canada could well be the last.
\end{abstract}

\section{The opportunity}

In this, the fourth decade of HIV, there is renewed hope and energy. The Joint United Nations Programme on HIVIAIDS (UNAIDS), has challenged all countries to strive for aggressive targets that could significantly bend the curve on HIV infections and deaths: $90 \%$ of people living with HIV diagnosed; $90 \%$ of people diagnosed on treatment; and $90 \%$ of people on treatment virally suppressed (1). Several countries, such as the United States and Australia, individual states and provinces (e.g.,

British Columbia), and cities (e.g., San Francisco) have launched ambitious treatment-focused strategies to reduce-and even end-new HIV infections.

This optimism is largely driven by strong research findings that early and ongoing HIV treatment improves individual health outcomes and reduces people's viral load, making them less infectious. Recent studies have also demonstrated the ability of pre-exposure prophylaxis (PrEP) to prevent infection in people at high risk of acquiring HIV $(2,3)$. 
Effective scale-up of HIV testing and treatment is essential. However, as the Lancet-UNAIDS Commission recently noted: it "... will not be sufficient to control the epidemic" if we do not address the stigma, discrimination, syndemics, and the social and structural drivers of the HIV epidemic (4).

\section{The impact of syndemics}

The risk of HIV infection is far from evenly distributed among populations most at risk. It is concentrated among those caught in a syndemic (synergistic epidemic) of intertwining health and social issues. For example, in the Multicenter AIDS Cohort Study (MACS) of 4,295 gay, bisexual and other men who have sex with men (MSM), Mimiaga et al. examined the effect of five psychosocial conditions on HIV incidence: depressive symptoms, heavy alcohol use, stimulant use, polydrug use, and childhood sexual abuse (5). Compared to those with none of these psychosocial health problems, an increasing number of these conditions was highly associated with HIV incidence, with men who had four or five of the conditions having an 8.7-fold increased risk of acquiring HIV over 48 months. Similar Canadian research takes this deeper by describing how social syndemics of marginalization experiences (harassment, career discrimination, physical violence, forced sex, suicidality) fundamentally contribute to the prevalence of similar psychosocial conditions among MSM (6).

In our Ontario HIV Treatment Network (OHTN) Cohort Study, which follows more than 5,000 people living with HIV in Ontario (about a third of all people currently in care), we are encouraged to see that most people who are part of that in-care cohort who receive care in specialized HIV clinics are nearing the 90-90-90 targets for being on antiretroviral therapy (ART) and for being virally suppressed (7); however, a different and concerning picture emerges when we examine those in care who have multiple psychosocial syndemic risks. Across all populations, those who experience a syndemic of co-occurring mental health and addiction issues are significantly more likely to fall out of care, less likely to adhere to treatment and less likely to achieve/maintain an undetectable viral load (8). (Note: people with HIV who are not part of this cohort may not be doing as well in terms of the 90-90-90 targets. Ontario is currently analyzing the cascade for the other two thirds of people living with HIV who are in care.) Other provinces are also seeing these complex factors affect health outcomes. The South Alberta HIV Program, for example, has identified high prevalence of domestic and intimate partner violence across all HIV risk groups, including MSM, and has documented its negative effects on engagement in HIV care, mental health and social stability $(9,10)$.

We are also learning about the impact of social determinants on mental health and HIV-related outcomes. According to our housing research in Ontario, funded by the Canadian Institutes of Health Research and the OHTN, people with HIV who are unstably housed are more likely to: have higher viral loads; be non-adherent to HIV treatment; not access medical or social services; have substance use issues; experience higher levels of depression and stress; and have higher mortality rates. In fact, incident depression is $50 \%$ higher in people who had difficulty affording housing-related expenses, and $60 \%$ higher in those who felt that they did not belong to their neighbourhood. In addition, those who were worried about being forced to move out, were significantly more likely to develop recurrent depression $(8,11)$. These results emphasize that social networks and context matter: when they are not safe, supportive and enabling, they can put individuals at risk of further negative health consequences.

Research in the United States and Canada has identified similar impacts related to food insecurity (12-14). People with HIV who are food insecure are less likely to have undetectable viral loads and have higher morbidity and mortality, and poorer physical and mental health-related quality of life (15). They miss more primary care appointments and make less use of HIV treatment. However, once they receive effective food and nutrition services, the picture changes dramatically: they are less likely to miss appointments, more likely to be on treatment, score higher in terms of mental health, and are more likely to be virally suppressed. 


\section{Using program science to tackle social and structural drivers}

The impact of syndemics reinforces the importance of a combination approach to HIV prevention and treatment that goes beyond primary care and mental health tools (16) to include protective social and structural interventions that can reduce risk and improve adherence-such as Housing First programs, access to harm reduction programs, effective interventions to reduce violence, and enabling social environments that help eliminate stigma and discrimination and protect human rights. Program science and implementation science offer new ways of thinking about pragmatic ways to mobilize research results and create effective, scalable and sustainable interventions in the real world (17-21). Program science is the "systematic application of theoretical and empirical scientific knowledge to improve the design, implementation and evaluation of public health programs" (19). Implementation science is a "multidisciplinary specialty that seeks generalizable knowledge about the behaviour of stakeholders, organizations, communities and individuals in order to understand the scale of, reasons for, and strategies to close the gap between evidence and routine practice for health in real-world contexts" (17).

There is no doubt that Canada has the knowledge, tools and resources to provide this type of programmatic, combination approach that can bring the HIV epidemic in this country to its knees. In Ontario, our new HIV strategy emphasizes the importance of working collaboratively across stakeholder groups (community, public health and health sectors) to give people living with and at risk of HIV better access to social and mental health services, as well as clinical treatment services that will help them achieve and maintain optimal health and well-being.

\section{Time for combination system-wide approaches}

We strongly encourage those in the HIV sector across the country to come together to learn from one another, and to identify a common vision with clear goals and targets-as well as the structures and interventions that will help achieve a cross-sectoral and combination approach-and then, through a focus on program and implementation science, make it happen.

At the clinical level, this means that, in addition to offering testing and treatment, the primary care/family or emergency room physician will routinely ask patients with or at risk of HIV about their housing, food security, experience of violence, mental health and substance use-and make appropriate referrals. At the program level, this means introducing efficacious social and structural interventions, and assessing their impact in different contexts and populations. At the policy level, this means developing policies-such as indicators for social outcomes - that enable the health care system to take effective combination interventions to scale.

\section{Take home message}

Biomedical approaches alone will not be enough to end HIV. We must tackle the social and structural drivers. With concerted and targeted efforts, a focus on program and implementation science, and a willingness to see and treat HIV as a social as well as a biomedical problem - the fourth decade of HIV in Canada could well be the last. 


\section{Acknowledgements}

The authors would like to thank all of the people living with HIV who volunteered to participate in the OHTN Cohort Study, the past and present members of the OHTN Cohort Study (OCS) Governance Committee for their work and support, and the nurses and physicians who provided support for data collection. In addition, we thank Public Health Ontario Laboratories for supporting record linkage with the HIV viral load test database.

\section{Conflict of interest}

None

\section{Funding}

The Ontario HIV Treatment Network (OHTN) Cohort Study is funded by the Ontario Ministry of Health and Long-Term Care (MOHLTC) AIDS Bureau. Funding for health research studies reported on housing and food security was provided by the Canadian Institutes of Health Research (CIHR). The findings, opinions and conclusions are those of the authors and no endorsement of these by CIHR or MOHLTC is intended or should be inferred.

\section{References}

(1) Joint United Nations Programme on AIDS (UNAIDS). 90-90-90-An ambitious treatment target to help end the AIDS epidemic. Geneva: UNAIDS; 2014 [cited 2015 Oct 20]. http://www.unaids.org/sites/default/files/media_asset/90-90-90_en_0.pdf

(2) Grant RM, Lama JR, Anderson PL, McMahan V, Liu AY, Vargas L, et al. Preexposure chemoprophylaxis for HIV prevention in men who have sex with men. N Engl J Med. 2010;363(27):2587-99.

(3) Baeten JM, Donnell D, Ndase P, Mugo NR, Campbell JD, Wangisi J, et al. Antiretroviral prophylaxis for HIV prevention in heterosexual men and women. N Engl J Med. 2012;367(5):399-410.

(4) Piot P, Abdool Karim SS, Hecht R, Legido-Quigley H, Buse K, Stover J, et al. A UNAIDS-Lancet Commission on Defeating AIDS-Advancing global health. Lancet. 2015 Jul 11;386(9989):171-218.

(5) Mimiaga MJ, O'Cleirigh C, Biello KB, Robertson AM, Safren SA, Coates TJ, et al. The effect of psychosocial syndemic production on 4-year HIV incidence and risk behavior in a large cohort of sexually active men who have sex with men. J Acquir Immune Defic Syndr. 2015 Mar 1;68(3):329-36.

(6) Ferlatte O, Hottes TS, Trussler T, Marchand R. Evidence of a syndemic among young Canadian gay and bisexual men: Uncovering the associations between anti-gay experiences, psychosocial issues, and HIV risk. AIDS Behav. 2014 Jul;18(7):1256-63.

(7) Burchell AN, Gardner S, Light L, Ellis BM, Antoniou T, Bacon J, et al. Implementation and operational research: Engagement in HIV care among persons enrolled in a clinical HIV cohort in Ontario, Canada, 2001-2011. J Acquir Immune Defic Syndr. 2015 Sep 1;70(1):e10-9.

(8) Rourke SB. Social and structural drivers affecting the health of people living with HIV. The North American Housing and HIVIAIDS Research Summit. Summit VIII: Tackling the Social Drivers of HIV; 2015 Sep 14-16; Washington, DC.

(9) Siemieniuk RA, Miller P, Woodman K, Ko K, Krentz H, Gill MJ. Prevalence, clinical associations, and impact of intimate partner violence among HIV-infected gay and bisexual men: A population-based study. HIV Med. 2013 May;14(5):293-302.

(10) Siemieniuk RA, Krentz HB, Miller P, Woodman K, Ko K, Gill MJ. The clinical implications of high rates of intimate partner violence against HIV-positive women. J Acquir Immune Defic Syndr. 2013 Sep 1;64(1):32-8

(11) Choi S. Impacts of housing-related conditions on prevalence, recurrence, and incidence of current depression among people living with HIV in Ontario over a five-year follow-up: Results from the Ontario HIV Treatment Network Cohort Study. The North American Housing and HIVIAIDS Research Summit. Summit VIII: Tackling the Social Drivers of HIV; 2015 Sep 14-16; Washington, DC.

(12) Anema A, Vogenthaler N, Frongillo EA, Kadiyala S, Weiser SD. Food insecurity and HIVIAIDS: Current knowledge, gaps, and research priorities. Curr HIVIAIDS Rep. 2009 Nov;6(4):224-31. 
(13) Weiser SD, Fernandes KA, Brandson EK, Lima VD, Anema A, Bangsberg DR, et al. The association between food insecurity and mortality among HIV-infected individuals on HAART. J Acquir Immune Defic Syndr. 2009 Nov 1;52(3):342-9.

(14) Anema A, Chan K, Chen Y, Weiser S, Montaner JS, Hogg RS. Relationship between food insecurity and mortality among HIV-positive injection drug users receiving antiretroviral therapy in British Columbia, Canada. PLoS ONE. 2013;8(5):e61277.

(15) Choi SK, Fielden S, Globerman J, Koornstra JJ, Hambly K, Walker G, et al. Food insufficiency, housing and health-related quality of life: Results from the Positive Spaces, Healthy Places study. AIDS Care. 2015 Sep;27(9):1183-90.

(16) Beyrer C, Sullivan PS, Sanchez J, Dowdy D, Altman D, Trapence G, et al. A call to action for comprehensive HIV services for men who have sex with men. Lancet. 2012 Jul 28;380(9839):424-38.

(17) Odeny TA, Padian N, Doherty MC, Baral S, Beyrer C, Ford N, et al. Definitions of implementation science in HIVIAIDS. Lancet HIV. 2015 May;2(5):e178-80.

(18) Glasgow RE, Chambers D. Developing robust, sustainable, implementation systems using rigorous, rapid and relevant science. Clin Transl Sci. 2012 Feb;5(1):48-55.

(19) Blanchard JF, Aral SO. Program science: An initiative to improve the planning, implementation and evaluation of HIV/sexually transmitted infection prevention programmes. Sex Transm Infect. 2011 Feb;87(1):2-3.

(20) Aral SO, Blanchard JF. The program science initiative: Improving the planning, implementation and evaluation of HIVISTI prevention programs. Sex Transm Infect. 2012 Apr;88(3):157-9.

(21) Glasgow RE, Vinson C, Chambers D, Khoury MJ, Kaplan RM, Hunter C. National Institutes of Health approaches to dissemination and implementation science: Current and future directions. Am J Public Health. 2012 Jul;102(7):1274-81. 